\title{
ESTUDO DA LIXIVIAÇÃO DE PLACAS DE CIRCUITO IMPRESSO DE COMPUTADORES DESKTOPS OBSOLETOS COM ÁCIDO SULFÚRICO
}

\author{
A. M. M. GOMES ${ }^{1}$, R. A. C. de MELO ${ }^{1}$, C. P. SOUZA' ${ }^{1}$, A. L. L. MORIYAMA ${ }^{1}$ e M. S. B. \\ da SILVA ${ }^{1}$
}

${ }^{1}$ Universidade Federal do Rio Grande do Norte, Departamento de Engenharia Química E-mail para contato: arthur.mendes@gmail.com

\begin{abstract}
RESUMO - A grande quantidade de lixo eletrônico produzido em decorrência da utilização crescente de equipamentos eletrônicos tem ocasionado problemas de sustentabilidade e poluição ao meio ambiente. A fim de minimizar esses impactos, é necessário desenvolver meios de reutilizar este tipo de resíduo. As placas de circuito impresso (PCI) possuem diversos metais preciosos (prata, ouro, etc.), de base (cobre, estanho, etc.) e pesados (chumbo, crômio, etc,). Por essa razão, o principal objetivo deste trabalho é estudar o processo de lixiviação das PCI utilizando ácido sulfúrico, visando a recuperação de elementos presentes em sua composição. As placas passaram por um processamento mecânico até atingir a morfologia de pó e posteriormente foi colocado em contato com soluções de ácido sulfúrico em diferentes condições de concentração e temperatura. O material lixiviado foi analisado gravimetricamente para determinar os percentuais de massa lixiviada e os ensaios foram executados seguindo um planejamento experimental fatorial para uma posterior análise estatística. Constatou-se que a temperatura foi o único fator significativo em relação a variável resposta.
\end{abstract}

\section{INTRODUÇÃO}

O uso de equipamentos eletrônicos tem crescido significativamente nos últimos anos devido a sua importância e utilidade no mundo moderno. O descarte e tratamento inadequado desses materiais vem causando problemas socioambientais, devido a presença de componentes tóxicos em sua composição. Exemplo disso, são as placas PCI que correspondem a $3,1 \%$ em peso dos resíduos de equipamentos eletrônicos (WIDMER et al, 2005).

As placas PCI podem possuir cádmio e chumbo em sua constituição, esses metais são considerados resíduos perigosos, pois podem contaminar o solo quando colocados em lixões ou aterros sanitários domésticos. Ao serem incinerados, as placas PCI liberam dioxinas e furanos, poluentes atmosféricos. Além disso, elas são constituídas de metais como ouro, prata, cobre e zinco, que possuem um grande potencial econômico se forem reaproveitados e colocados de volta na cadeia produtiva.

A recuperação dos metais presentes nas PCI pode ser feita por meio da hidrometalurgia. Esse processo envolve a utilização de soluções ácidas para dissolver metais de interesse. A 
solução com metal dissolvido, chamado de extrato lixiviado, é submetida a precipitações de impurezas, extrações por solvente ou líquido-líquido, adsorção e troca iônica com objetivo de separar e purificar os metais que, posteriormente, passarão por processos eletrolíticos, de redução ou cristalização para serem recuperados

\section{METODOLOGIA}

Foram utilizadas placas de circuito impresso de computadores desktops obsoletos de diferentes marcas e modelo. Inicialmente, as PCI foram desmanteladas para retirar os diferentes componentes eletrônicos fixados à superfície da mesma com o intuito de otimizar o processo de reciclagem das diversas partes existentes. Em seguida, as PCI desmanteladas foram cortadas em fragmentos menores de aproximadamente $4 \mathrm{~cm}^{2}$ com auxilio de uma guilhotina tesourão para facilitar a etapa seguinte de cominuição realizada em moinho de facas de oito lâminas. Depois disso o material moído foi separado granulometricamente utilizando uma peneira de $1 \mathrm{~mm}$ de abertura. A fração de PCI com granulometria superior a 1 $\mathrm{mm}$ (retido na malha da peneira) passou por mais uma etapa de moagem.

Os ensaios de lixiviação foram realizados utilizando o ácido sulfúrico como reagente. A reação deu-se por um período de 6 horas em um balão volumétrico de $500 \mathrm{~mL}$ com três juntas esmerilhadas acoplado a um termômetro para controle da temperatura e um condensador de bolas para refluxo dos vapores ácidos produzidos. Foi utilizado $200 \mathrm{~mL}$ de solução e $10 \mathrm{~g}$ de PCI moída e quarteada. Os ensaios de lixiviação foram executados seguindo um planejamento experimental fatorial completo $2^{2}$ com três repetições no ponto central, sendo a temperatura (T) e a concentração molar do ácido (C) as duas variáveis independentes e o percentual de massa lixiviada (L) a variável dependente resposta medida por análise gravimétrica (balanço de massa). Os níveis das variáveis independentes testadas são apresentados na Tabela 1.

Tabela 1 - Níveis das variáveis utilizadas nos ensaios de lixiviação.

\begin{tabular}{cccc}
\hline \multirow{2}{*}{ Fatores } & \multicolumn{3}{c}{ Níveis } \\
\cline { 2 - 4 } & $\mathbf{- 1}$ & $\mathbf{0}$ & $\mathbf{+ 1}$ \\
\hline Concentração molar do ácido $(\mathbf{m o l} / \mathrm{L})$ & 2 & 3 & 4 \\
Temperatura do sistema $\left({ }^{\circ} \mathbf{C}\right)$ & 50 & 65 & 80 \\
\hline
\end{tabular}

\section{RESULTADOS E DISCUSSÕES}

Os progressos obtidos em cada uma das etapas realizadas durante o processamento mecânico das placas de circuito impresso são apresentados na Figura 1. 


\section{C \\ CONGRESSO BRASILEIRO DE ENGENHARIA \\ QUÍMICA EM INICIACC̃O CIENTÍFICA}

Figura 1 - Etapas do processamento mecânico das PCI: (a) PCI coletada; (b) PCI desmantelada; (c) PCI cortada; (d) PCI moída.

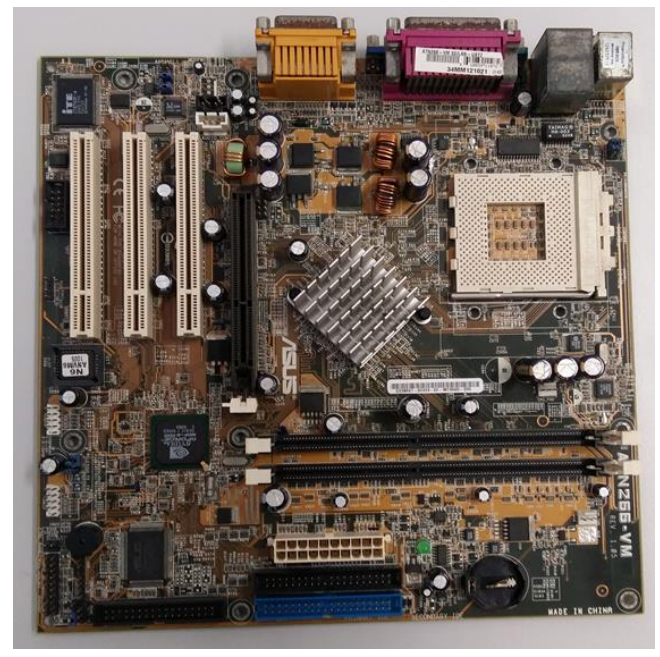

(a)

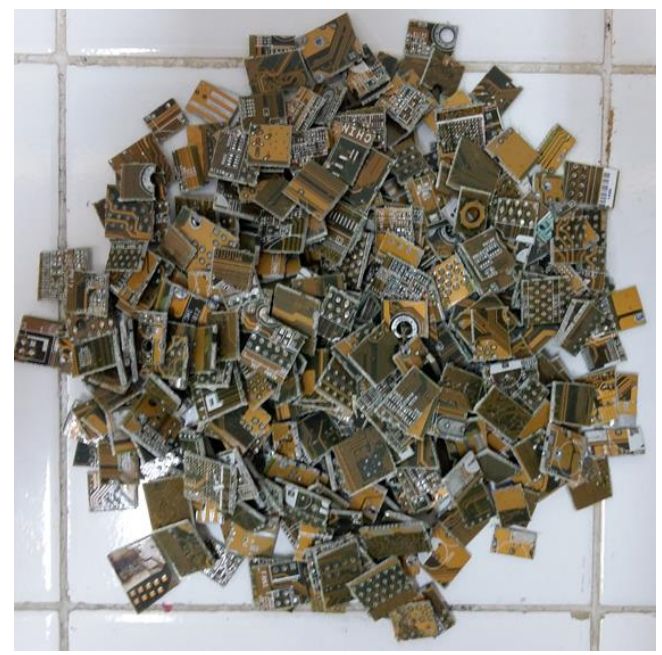

(c)

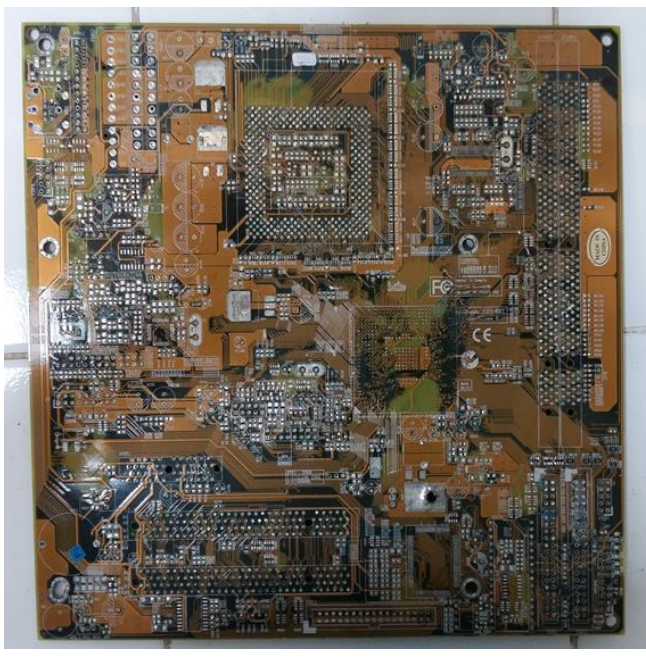

(b)

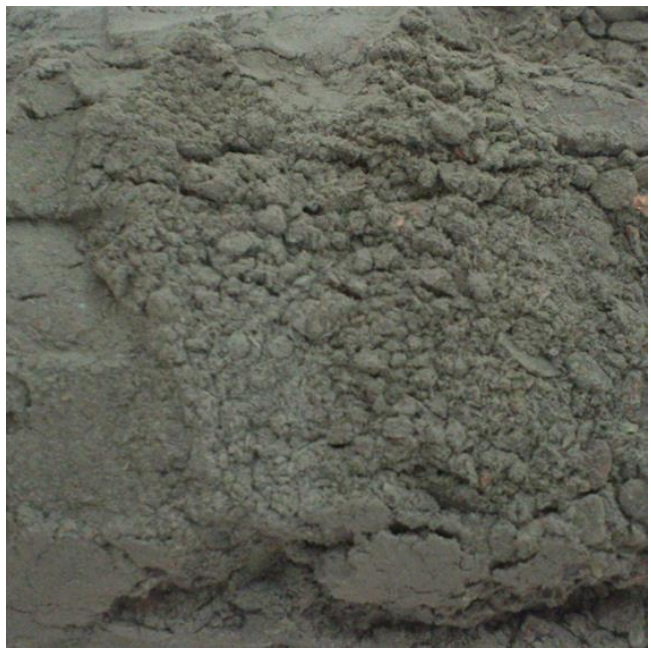

(d)

O rendimento alcançando durante a etapa de moagem foi de aproximadamente $96 \%$ em massa, ou seja, apenas $4 \%$ do material foi perdido na forma de poeira ou por impregnação no moinho de facas utilizado. Este rendimento é considerado satisfatório quando comparamos com outros estudos que normalmente registram perdas de massas bem superiores, podendo chegar até a $20 \%$ em perdas de massa (Kasper, 2012).

Os resultados dos percentuais de massa lixiviada (L), obtidos por balanço de massa (análise gravimétrica) - considerando os quantitativos de material em fase sólida pesados antes e depois da lixiviação - para cada um dos ensaios do planejamento experimental executado são apresentados na Tabela 2. 
Tabela 2 - Matriz do planejamento experimental.

\begin{tabular}{|c|c|c|c|c|}
\hline Ensaio & $\begin{array}{c}\mathrm{T} \\
\left({ }^{\circ} \mathrm{C}\right)\end{array}$ & $\begin{array}{c}\mathrm{C} \\
(\mathrm{mol} / \mathrm{L})\end{array}$ & $\begin{array}{c}\mathrm{L} \\
(\%)\end{array}$ & $\begin{array}{c}\text { Ordem de } \\
\text { Execução }\end{array}$ \\
\hline \hline 1 & 50 & 2 & 17,44 & $(3)$ \\
\hline 2 & 80 & 2 & 19,37 & $(1)$ \\
\hline 3 & 50 & 4 & 15,05 & $(4)$ \\
\hline 4 & 80 & 4 & 20,12 & $(2)$ \\
\hline 5 & 65 & 3 & 17,72 & $(5)$ \\
\hline 6 & 65 & 3 & 17,30 & $(6)$ \\
\hline 7 & 65 & 3 & 18,15 & $(7)$ \\
\hline
\end{tabular}

Pelos resultados da análise gravimétrica percebe-se uma variação significativa nos valores obtidos para o percentual de massa lixiviada a depender dos níveis dos fatores testados. O melhor rendimento de lixiviação alcançados foi de $20,12 \%$ para temperatura de 80 ${ }^{\circ} \mathrm{C}$ e concentração molar do ácido de $4 \mathrm{~mol} / \mathrm{L}$. Já o menor rendimento alcançado foi de $15,05 \%$ para temperatura de $50{ }^{\circ} \mathrm{C}$ e concentração molar do ácido de $4 \mathrm{~mol} / \mathrm{L}$.

Após os ensaios de lixiviação um estudo estatístico para o planejamento experimental proposto foi realizado utilizando os resultados da análise gravimétrica para determinar quais fatores analisados apresentaram efeito significativo sobre a variável resposta, bem como 0 coeficiente de regressão $\left(\mathrm{R}^{2}\right)$ do modelo linear proposto (ver Tabela 3 ).

Tabela 3 - ANOVA do planejamento experimental.

\begin{tabular}{|l|l|l|l|l|c|}
\hline \multicolumn{7}{|c|}{ Efeito estimado, $\mathrm{R}^{2}=0,9689$} \\
\hline \hline \multicolumn{1}{|c|}{ Fatores } & \multicolumn{1}{c|}{ SS } & df & \multicolumn{1}{c|}{ MS } & \multicolumn{1}{c|}{ F } & p \\
\hline \hline (1) Temperatura $\left({ }^{\circ} \mathbf{C}\right)$ & $\mathbf{1 2 , 2 1 6 8 6}$ & $\mathbf{1}$ & $\mathbf{1 2 , 2 1 6 8 6}$ & $\mathbf{6 6 , 9 3 4 8 5}$ & $\mathbf{0 , 0 1 4 6 1 3}$ \\
\hline$(2)$ Concentração $(\mathrm{mo} / \mathrm{L})$ & 0,67364 & 1 & 0,67364 & 3,69082 & 0,194670 \\
\hline$(1)$ x $(2)$ & 2,45853 & 1 & 2,45853 & 13,47004 & 0,066877 \\
\hline Falta de Ajuste & 0,12761 & 1 & 0,12761 & 0,69918 & 0,491045 \\
\hline \hline Erro Puro & 0,36504 & 2 & 0,18252 & & \\
\hline \hline Soma Total & 15,84169 & 6 & & & \\
\hline
\end{tabular}

O coeficiente de correlação $\left(\mathrm{R}^{2}\right)$ estimado para o modelo linear apresentado foi próximo da unidade $(0,9689)$ indicando que o mesmo apresenta um bom ajuste aos dados experimentais. De acordo com a tabela ANOVA a temperatura é trazida em destaque como única variável significativa do processo de lixiviação com ácido sulfúrico. Ainda, a falta de ajuste não foi apresentada como fator significativa por não ser trazida em destaque, indicando assim que o modelo é valido/preditivo para o intervalo dos parâmetros avaliados

A seguir são apresentados os gráficos de superfície de resposta e curva de contorno considerando o percentual de massa lixiviada em função da temperatura e concentração molar do ácido (ver Figura 2). 
Figura 2 - (a) superfície de resposta; (b) curvatura de contorno.

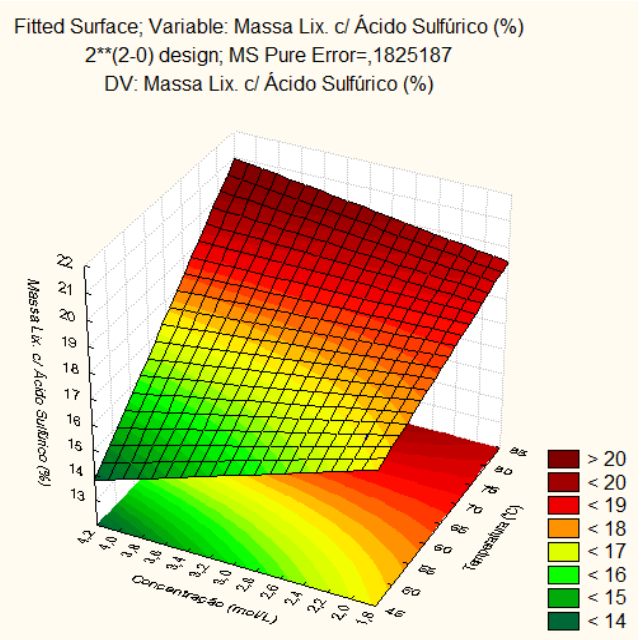

(a)

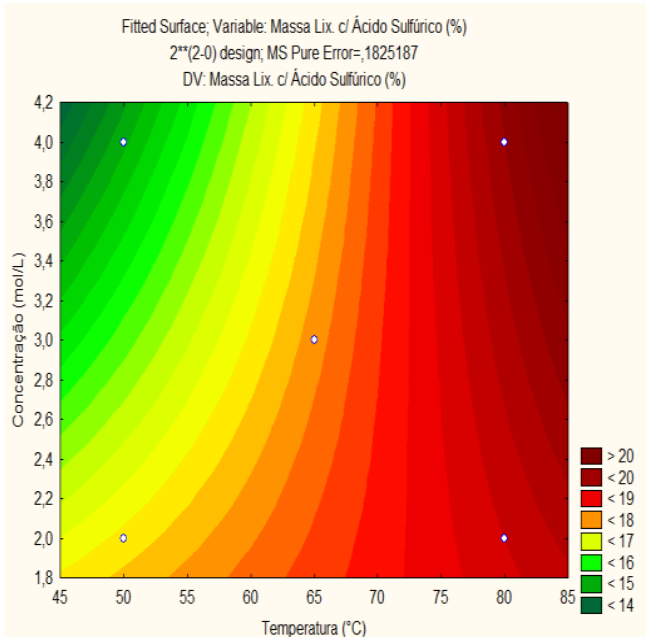

(b)

Pelos gráficos apresentados acima percebe-se com mais clareza os efeitos produzidos tanto pela temperatura quanto pela concentração molar do ácido sobre a variável resposta. Pela a inclinação do gráfico, percebe-se que o efeito da temperatura é mais pronunciado sobre a variável resposta que o efeito da concentração molar do ácido, como foi observado na tabela da ANOVA que mostrou a temperatura como única varável significativa. Ainda, o aumento do percentual de massa lixiviada foi diretamente proporcional ao aumento da temperatura. Por outro lado, o aumento da concentração molar do ácido apresentou efeito negativo sobre a variável resposta para baixas temperatura e positivas para temperaturas mais elevadas

\section{CONCLUSÃO}

Os ensaios de lixiviação utilizando ácido sulfúrico na dissolução dos metais presentes nas PCI obtiveram maiores percentuais de massa lixiviada realizados à $80^{\circ} \mathrm{C}$. Sendo o melhor rendimento de lixiviação na análise gravimétrica de $20,12 \%$ para $80^{\circ} \mathrm{C}$ e concentração molar de ácido de $4 \mathrm{~mol} / \mathrm{L}$ e o menor valor de $15,05 \%$ para $50^{\circ} \mathrm{C}$ e concentração de $4 \mathrm{~mol} / \mathrm{L}$.

Pelo o estudo estatístico dos resultados das análises gravimétricas constatou-se que a temperatura é a variável mais significativa do processo de lixiviação com ácido sulfúrico, visto que temperaturas maiores resultaram em maiores percentuais de massa lixiviada. $O$ valor próximo da unidade para o coeficiente de correlação $(0,9689)$ indica que o modelo de primeira ordem proposto se ajusta bem aos dados experimentais. Outra conclusão importante pode ser retirada dos gráficos de superfície de resposta e curvatura de contorno que demonstram que apesar dos efeitos da temperatura serem bem mais pronunciado, menores concentrações de ácido favorecem maiores percentuais de PCI lixiviadas.

Esse processo tem potencial para o desenvolvimento de uma nova rota hidrometalúrgica usando ácido sulfúrico no tratamento e reciclagem de resíduos de equipamentos eletroeletrônicos. A implementação desse processo possui potencial econômico, já que 
promove a reutilização dos metais na cadeia produtiva, além de diminuir os impactos ambientes causados pelo descarte inadequado desse tipo de resíduo perigoso contendo metais pesados em lixões.

\section{REFERÊNCIAS}

CARVALHO, T. C. M. B.; XAVIER, L. H. Gestão de resíduos eletroeletrônicos: uma abordagem prática para a sustentabilidade. Rio de Janeiro: Elsevier, 2014.

KASPER, A. C. A. Caracterização e reciclagem de materiais presentes em sucatas de telefones celulares. Dissertação (Mestrado) - Programa de Pós-Graduação em Engenharia de Minas, Metalúrgica e de Materiais, Escola de Engenharia, Universidade Federal do Rio Grande do Sul, Porto Alegre, 2011.

MORAES, V. T. Recuperação de metais a partir do processamento mecânico e hidrometalúrgico de placas de circuito impresso de celulares obsoletos. Tese (Doutorado) Escola Politécnica, Universidade de São Paulo, São Paulo, 2011.

OLIVEIRA, P. C. F. Valorização de placas de circuito impresso por hidrometalurgia. Tese (Doutorado) - Instituto Superior Técnico, Universidade Técnica de Lisboa, Lisboa, 2012.

VEIT, H. M. Reciclagem de cobre de sucatas de placas de circuito impresso. Tese (Doutorado) - Programa de Pós-Graduação em Engenharia de Minas, Metalúrgica e de Materiais, Escola de Engenharia, Universidade Federal do Rio Grande do Sul, Porto Alegre, 2005.

WIDMER, R. Global perspective on e-waste. Environmental Impact assessment review, v. 25:2005, pp. 436-458. 